\title{
Prevalence and pattern of menstrual problems and relationship with some factors among Saudi nursing students
}

\author{
Najwa Karout * \\ Ibn Sina National College for Medical Sciences, Jeddah, Saudi Arabia
}

Received: June 23, 2015

Accepted: August 11, 2015

Online Published: August 25, 2015

DOI: $10.5430 /$ jnep.v5n12p1

URL: http://dx.doi.org/10.5430/jnep.v5n12p1

\begin{abstract}
Background: Menstrual problems affect not only women, but also families, social and national economy as well. These problems for women in developing countries who may face life-threatening conditions are considered as minor health concern. Identification of abnormal menstrual patterns throughout adolescence may permit early identification of potential health concerns for adulthood. Nurses play a key role central to public education and prevention on menstrual hygiene among female adolescents.

Methods: Analytic method based on cross sectional survey was undertaken on 342 nursing students in Al Khobar city. Taking in consideration the ethical issues the data collected by using a valid, self-administered questionnaire including close ended questions to assess the menstrual patterns and prevalence of menstrual problems among Saudi nursing students also to examine any relationship between the menstrual problems with the demographic data and menarcheal age.

Results: Serious percentages of students who were suffered from many kinds of menstrual problems, some significant relationships between menstrual problems and some factors such as the academic year, marital status, menarcheal age, and mother education level found but not with age.

Conclusions: The findings reported high prevalence of menstrual problems and their implication on the quality of life, this indicates the importance of the health team role especially the nurse in health education about menstrual problems targeting the community as well as teaching about female reproductive system and its function in the schools that could contribute in early detection of the menstrual dysfunctions.
\end{abstract}

Key Words: Menstruation problems, Pattern, Menstrual disorders, Saudi Arabia, Eastern Province

\section{INTRODUCTION}

The disorders related to menstruation are the greatest common gynecologic illnesses. The highest percentage is among 20 to 24-year old age group then it reduces increasingly afterward. They touch not only females, they affect also families, public and general economy too. ${ }^{[1]}$ In general, menstrual disorders are supposed to be negligible concerns especially in the developed countries where the women suffer from dangerous problems therefore they are inappropriate to the community health plan. ${ }^{[2]}$

Clinical evidence from literature review indicates that starting from the third year after menarche, the interval between bleeding periods is in the range of 21-34 days, with a flow lasting 3 to 7 days and a mean menstrual blood loss of $35 \mathrm{ml}$ (range $5-80 \mathrm{ml}){ }^{[3]}$ Variability in menstrual patterns and dysfunctions, such as dysmenorrhea, pain, duration, and

*Correspondence: Najwa Karout; Email: nkkarout@yahoo.com; Address: Ibn Sina National College for Medical Sciences, Jeddah, Saudi Arabia. 
frequency, has been described for different adolescent populations. ${ }^{[4]}$

Menstrual problems include menstrual cycle irregularities (of duration or length), hyper-or hypomenorrhoea, poly-or Oligomenorrehoa, dysmenorrhea, amenorrhea, menorrhagia and premenstrual syndrome (PMS). These problems are major source of anxiety to them and their families. ${ }^{[5]}$ Early detection, assessment and cure of menstrual problems sometimes can help in the cases related to bone compactness and risk factor and could delay the progress of osteoporosis and hip fracture. ${ }^{[6]}$

Menstrual irregularity was reported in $43 \%$ to $62 \%$ of girls during their first year of menstruation and in some it persists for 3 to 5 years. ${ }^{[7]}$ Among adolescent girls, it was reported to have menstrual dysfunction and is known to affect the normal daily chores. Delayed, irregular, painful, and heavy menstrual bleeding are common occurrence among younger age and are the leading reasons for physician office visited by adolescents. ${ }^{[8]}$ Nonetheless dysmenorrhea is the most common being reported in $60 \%$ to $90 \%$ of adolescent frequent cause of absenteeism from school or restriction of daily activity. ${ }^{[7]}$ It is yet another major cause of activity restriction and school absenteeism in adolescent girls. However, the condition is often considered as physiological pain and generally ignored. A few of the adolescents consult physician for the problem and many adopt self-medication with over-the-counter medicines or home remedies. ${ }^{[9]}$

As the females' age increases, the percentage of dysmenorrhea decreases. The highest percentage is among 20 to 24-year old age group then it reduces increasingly afterward. Conversely, another common problem highly affects girls and women during their reproductive live known as premenstrual syndrome. Those problems, dysmenorrhea and PMS affect negatively the woman's life. ${ }^{[1]}$

Identification of the prevalence and patterns of menstrual problems among the females helps in the early detection of reproductive health disorders during maturity period. Amenorrhea is one of the few problems challenging the gynecologic endocrinologist as a complex. Yet, by assessment of those problems will give chance for early diagnosis and treatment of conditions affecting the hypothalamic-pituitaryovarian (HPO) axis. ${ }^{[6]}$

The purpose of this study was to assess the menstrual patterns and prevalence of menstrual problems among Saudi nursing students also to examine any relationship between the menstrual problems with the demographic data and menarcheal age.

\section{METHODS}

\subsection{Study design}

A cross sectional survey was conducted, in nursing college in Al Khobar city at Eastern province in Saudi Arabia, the population was all the nursing students from different academic years; all 400 female students registered in the academic year 2013-2014 in all academic years were included in the study as a sample in order to reduce the effect of non-responses. These students represent the adolescents Saudi girls from Eastern province in Saudi; this sample size was adequate as the previous studies which used the appropriate size.

\subsection{Data collection}

Data were collected in January 2013 by taking permission from the college authority based on the students' academic schedule, 400 questionnaires distributed to the students in their class. The questionnaires took about 30 minutes to complete. The data was collected using a valid, self-administered, anonymous questionnaire, included demographic data, menstrual patterns, and menstrual problems; all the questions were close ended. The robustness of the questionnaire had been achieved by reviewing the previous similar studies as content validity and by using $\mathrm{t}$-test by conducting a pilot study for reliability.

Menstrual problems define as follows: ${ }^{[10]}$

- Secondary amenorrhea: During the last three months there is no menstruation.

- Regular Period: The menstruation repeated once every twenty eight to thirty two days.

- Oligomenorrehoa: The menstruation is repeated every more than thirty two day.

- Polymenorrhoea: The menstruation is repeated every less than twenty one day.

- Hypomenorrhoea: The amount of blood loss less than 3 pads and the duration of the period equal or less than three days.

- Hypermenorrehoa: The amount of blood loss more than five pads and the duration of the period equal or more than seven days.

- Dysmenorrhea: Pain during period which is characterized 3 patterns mild, moderate or severe.

- PMS: Is a multi-symptom that happened ten days before the starting of the menstruation, some of those symptoms such as bloating or swelling of the abdomen or painful or tender breasts, rapid mood change and, depressed mood. Having at least three of these symptoms in condition that those symptoms should vanish at the start of menstruation will consider as PMS. 


\subsection{Ethical consideration}

The proposal went under discussion and evaluation by the research ethical committee of the college of nursing, after approval and related permission, the questionnaires distributed taking in consideration the ethical issues. The researcher clarified the aim and the goals of the study and also explained to the students that the participation in the study is not obligatory, in addition it was stressed on the confidentiality of the data that will be collected, and the students also were asked to sign the informed consent that was attached to the questionnaire.

\subsection{Data analysis}

The software SPSS version 17 used to analyze the collected data. Data were revised and coded and tabulated using the frequency and percentage, to analyze and interpret the results, logistic regression and odds ratio were used to test the significance of the variables with $p<.05$.

\section{RESULTS}

\subsection{Back ground characteristics}

Of the 400 students recruited to the study the number of responding were 342 participants $(85.5 \%)$, the majority of the students $(53.5 \%)$ were between $18-20$ years old and $81 \%$ were single (see Table 1).

According to academic level, $80.4 \%$ were in under 3rd year. In addition the mother's educational level was among the majority of the participants $(52.9 \%)$ equal or less intermediate (see Table 1).

\subsection{Pattern and problems of menstruation}

Menarcheal age: The results in Table 2 about menarche history of the participants showed that $7.6 \%$ of the participants had the onset of menstruation at age less than 10 years old and $61.4 \%$ were between 11 and 14 also $28 \%$ of the participants their menarcheal age were older than 14 years.

Menstrual irregularity: $36.4 \%$ of the participants had irregular menstruation. Secondary amenorrhea: Considering those who were pregnant and breast feed, $2.9 \%$ had secondary amenorrhea. Frequency and blood amount: $21.6 \%$ and $21.3 \%$ of the participants had oligo and polymenorrhoea respectively. Also $6.7 \%$ and $9.1 \%$ had respectively hypomenorrhoea and hypermenorrehoa. $19.5 \%$ and $12.5 \%$ of the participants used respectively less than 3 pads and more than 5 pads as amount of blood.

Dysmenorrhea: The results in Table 3 show that, $96.3 \%$ of the participants had dysmenorrhea, in which $35.8 \%$ were suffering from severe dysmenorrhea, $47.5 \%$ moderate and $13.2 \%$ mild.

Published by Sciedu Press
The location of the pain among those who had dysmenorrhea was $18.7 \%$ and $30.9 \%$ in abdomen and abdomen that extended down to the thighs respectively. $13.4 \%$ of the participant had back pain and $8.1 \%$ the dysmenorrheal pain located in back and extended down to the anus. $30.2 \%$ of the participants had other pain location. According to the impact of dysmenorrhea on their life, among those having dysmenorrhea, $94.5 \%$ announced that having dysmenorrhea reduced their daily activity and $65.7 \%$ of them became absent from college.

Table 1. Background characteristics of the sample of the students $(n=342)$

\begin{tabular}{lll}
\hline Variable & Frequency & Percent (\%) \\
\hline Age & & \\
Less than 18 & 23 & 6.7 \\
$18-20$ & 183 & 53.5 \\
$21-23$ & 114 & 33.3 \\
$>23$ & 22 & 6.5 \\
Marital status & & \\
$\quad$ Single & 277 & 81.0 \\
$\quad$ Married & 65 & 19.0 \\
Academic year & & \\
$\quad$ Foundation-3 & \\
$\quad$ Third Year & 275 & 80.4 \\
Mother education & 67 & 19.7 \\
$\quad$ Intermediate & 182 & \\
$\quad$ Intermediate & 160 & 52.9 \\
\hline
\end{tabular}

Table 2. Distribution of menarcheal age among nursing students $(n=342)$

\begin{tabular}{lll}
\hline Age of Menarche & Frequency & Percent (\%) \\
\hline$<10$ & 26 & 7.6 \\
$11-14$ & 210 & 61.4 \\
$>14$ & 96 & 28.0 \\
\hline
\end{tabular}

PMS: The results in table 4 show that, $95.6 \%$ of the participants had at least 3 symptoms, in which $46.2 \%$ of them the symptoms did not disappear by the onset of menstruation and $52.7 \%$ of them disappeared.

Among those who had PMS, 52.7\% of them announced that having PMS, reduced the productivity, and 51.2\% interfere with their hobbies or social activities. In addition PMS interfered with relationships among $48.0 \%$ of the participants.

\subsection{Logistic regression analysis.}

To understand the relationship between menstrual problems and some factors and after allowing for other confounding variables, the results of logistic regression of output, revealed 
the following:

Those who were single are significantly suffered from dysmenorrhea comparing with married ones (Exp B $=0.30, P$ $=.04)$. Those who were married, significantly had amenorrhea during the last 3 months compared with the single ones ( $\operatorname{Exp} \mathrm{B}=3.78, P=.00)$. In addition to that, those who were married, significantly suffered from hypermenorrehoa (using $>5$ pads) compared with the single students (Exp B= $0.15, P=.01)$. It was also found that who were under the $3 \mathrm{rd}$ academic year had significantly $(\operatorname{Exp} B=2.07, P=.00)$ suffered from PMS compared with those who were up to the 3rd academic year. Also those who were less than 3rd academic year had significantly (Exp B $=4.44, P=.01$ ) suffered from Hypomenorrhoea compared with those who were above the 3rd academic year. It was found also that those who had early menarche $<10$ years had significantly $(\operatorname{Exp~B}=9.14, P$ $=.00$ ) suffered from hypomenorrhoea compared with those who had normal menarcheal age (between 11-14 years). The results showed that those who had menarcheal age more than 14 years old, significantly had irregular menstruation compared with those who had menarcheal age between 11-14 years old (Exp B $=0.52, P=.04)$. Nonetheless, those who had early menarcheal age $(<10$ years) significantly (Exp B $=2.7, P=0.01)$ had Oligomenorrehoa compared with those who had menarcheal age between 11-14 years old. Also the results showed that those who had regular menstruation had significantly the mother's education level more than intermediate $(\operatorname{Exp} B=0.62, P=.04)$ (see Figure 1).

Table 3. Prevalence and pattern of dysmenorrhea among nursing students $(n=342)$

\begin{tabular}{llll}
\hline Dysmenorrhea & & Frequency & Percentage (\%) \\
\hline \multirow{2}{*}{ Pain severity } & Mild & 45 & 13.2 \\
& Moderate & 162 & 47.5 \\
From those who had dysmenorrhea & Severe & 123 & 35.8 \\
& Abdomen & $\mathbf{N}=\mathbf{3 3 0}$ & $\mathbf{9 6 . 5}$ \\
Location & Abdomen extended to thighs & 62 & 18.7 \\
& Back & 102 & 30.9 \\
& Back extended to anus & 44 & 13.4 \\
Impact & Other location & 27 & 8.1 \\
& Reduced daily activity & 103 & 31.2 \\
\hline
\end{tabular}

Table 4. Prevalence and pattern of PMS among nursing students $(n=342)$

\begin{tabular}{llll}
\hline PMS & & Frequency & Percentage (\%) \\
\hline Presence & Yes & 161 & 95.6 \\
Disappear after onset & Yes & 181 & 52.7 \\
From those who had PMS & & $\mathbf{N}=\mathbf{1 8 1}$ & $\mathbf{5 2 . 7}$ \\
& Reduced daily productivity & 95 & 52.6 \\
Impact & Interfered with hobbies and social activities & 94 & 51.2 \\
& Interfered with relationships & 86 & 48 \\
\hline
\end{tabular}

\section{Discussion}

Menstrual problems are considered as the common reason of referral to the gynecologists, and these problems have a considerable effect on the life of the women and their health. ${ }^{[11]}$ Menstrual problems have some privacy in some community thus they do not find interest in the community. ${ }^{[12,13]}$

In the current study, the results showed that the majority of the participants $(53.5 \%)$ were between 18-20 years old, comparable to other studies, mean age in Lebanon $(20.9),{ }^{[10]}$
Bahir (20.4) ${ }^{[1]}$ and Nigeria (21.1). ${ }^{[2]}$ This group of age, is usually suffers from menstrual problems; ${ }^{[3]}$ furthermore $81 \%$ were single relevant to the results showed in previous studies (92.3\% in Bahir, ${ }^{[1]}$ Lebanon $\left.86.7 \%{ }^{[10]}\right)$. In this study the majority of the participants $(61.4 \%)$ had menarcheal age between 11 and 13 years old which is normal but $7.6 \%$ of the participants had the menarcheal age less than 10 years old and $26 \%$ more than 14 years old .This age is comparable to those reported among girls from British and other European and American cities. ${ }^{[4]}$ 
Table 5. Logistic regression analysis of factors affecting menstrual problems among nursing students $(\mathrm{n}=342)$

\begin{tabular}{|c|c|c|c|c|}
\hline Menstrual problems & Factors & B & $P$ value & OR (85\% CI) \\
\hline$<3$ pads or $>5$ pads & \multirow{5}{*}{ Marital status } & -0.14 & .06 & $0.8(0.4-1.5)$ \\
\hline Dysmenorrhea & & -1.18 & .04 & $0.3(0.09-0.99)$ \\
\hline Amenorrhea last 3 months & & 1.33 & .00 & $3.7(2.0-7.0)$ \\
\hline Hypermenorrehoa (> 7 days ) & & -0.37 & .01 & $0.1(0.1-2.4)$ \\
\hline PMS & & -0.2 & .4 & $0.1(0.4-1.3)$ \\
\hline Polymenorrhoea & \multirow{4}{*}{ Late menarche $>14$ years } & 0.2 & .3 & $1.3(0.7-0.2)$ \\
\hline Irregular menstruation & & 0.65 & .04 & $0.5(0.2-0.9)$ \\
\hline Hypermenorrhea & & -0.10 & .7 & $0.9(0.3-1.5)$ \\
\hline Hypomenorrhoea(<3 days ) & & -0.45 & .4 & $0.6(0.2-1.9)$ \\
\hline Hypermenorrhea & \multirow{5}{*}{ Early menarche $<10$ years } & -0.6 & .2 & $1.8(0.6-5.0)$ \\
\hline Polymenorrhoea & & 1.01 & .01 & $2.7(1.18-6.4)$ \\
\hline Hypomenorrhoea & & 2.2 & .00 & $9.1(2.7-30.4)$ \\
\hline Irregular menstruation & & 0.4 & .3 & $0.6(0.2-1.5)$ \\
\hline PMS & & -0.1 & .7 & $1.1(0.4-2.9)$ \\
\hline Irregular menstruation & \multirow{3}{*}{ Academic year } & 0.3 & .2 & $1.4(0.7-2.6)$ \\
\hline PMS & & 0.7 & .00 & $2.0(1.2-3.5)$ \\
\hline Hypomenorrhoea & & 1.4 & .01 & $4.4(1.3-14.9)$ \\
\hline PMS & \multirow{3}{*}{ Age } & -0.6 & .8 & $0.9(0.3-2.2)$ \\
\hline Irregular menstruation & & 0.2 & .6 & $1.2(0.4-3.1)$ \\
\hline Dysmenorrhea & & 0.9 & .2 & $2.6(0.5-12.8)$ \\
\hline Irregular menstruation & \multirow{4}{*}{ Mother education } & 4.7 & .04 & $0.6(0.3-0.9)$ \\
\hline PMS & & 0.3 & .7 & $1.4(0.9-2.2)$ \\
\hline Hypomenorrhoea & & 0.6 & .2 & $1.8(0,6-5)$ \\
\hline Dysmenorrhea & & 0.3 & .5 & $1.4(0.4-4)$ \\
\hline
\end{tabular}

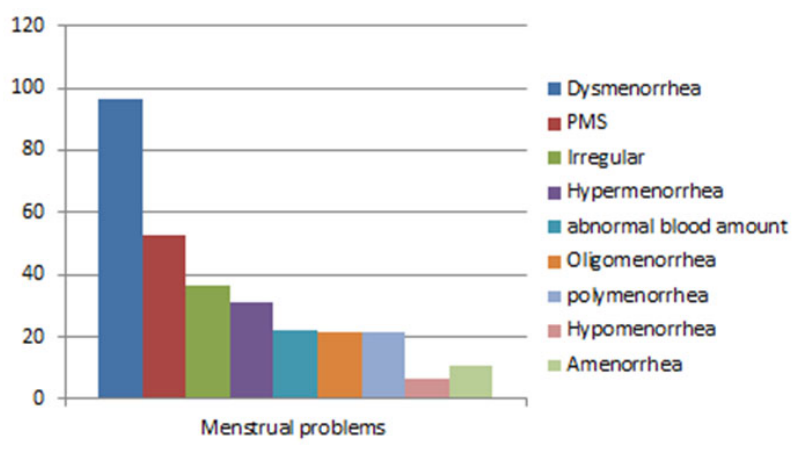

Figure 1. Prevalence of Menstrual problems among Saudi nursing students $(\mathrm{n}=342)$

Logistic regression analysis showed that the odds of having hypomenorrhoea among those who had early menarche is 9 times more than those who had a normal menarcheal age.

Also the odds of having irregular menstruation among those who had late menarcheal age is 0.5 times more than those who had a normal menarcheal age.

Published by Sciedu Press
In addition the odds of having Oligomenorrehoa among those who had early menarcheal age is 2.7 times more than those who had a normal menarcheal age.

In a previous study the inverse relation between age of menarche and blood loss was found to have statistically significant association $(P=.029)$. It is also evident that higher percentage of girls who encompassed menarche at an earlier age experienced dysmenorrhea more than those who had late menarche $(P=.001) .{ }^{[9]}$

In adolescence period it is common having irregular cycle during the initiating of menstruation because of nonovulatory cycle, in consequences will have abnormal bleeding that may increase to become menorrhagia. ${ }^{[14]}$ In our study $36.4 \%$ had irregular menstruation, less than Ethiopian students (46.2\%), ${ }^{[1]}$ and Saudi (41.5\%), ${ }^{[16]}$ and similar to Jordanian girls $(34.6 \%),{ }^{[4]}$ whereas $21.6 \%$ and $21.3 \%$ of the participants had oligo and polymenorrhoea respectively.

Our current study showed that $6.7 \%, 9.1 \%$ had respectively hypomenorrhoea and hypermenorrehoa, also 19.5\%, $4.3 \%$ 
had respectively less than one pad and more than 5 pads as amount of blood.

This may be because of changing trends in lifestyle, dietary habit, stress, hormonal imbalance or some medical reasons which requires gynecological assessment at the earliest.

This finding is more than a previous study in central India, found that $13.73 \%$ girls had Oligomenorrehoa and $8.38 \%$ had polymenorrhoea, ${ }^{[14]}$ and more than the finding among tribal Gujjar girls as $9.9 \%$ of the subjects had Oligomenorrehoa. ${ }^{[15]}$

In the present study logistic regression showed that the odds of having hypomenorrhoea among those who were below the 3 rd academic year is 4 times more than those who were above the 3rd academic year.

The results of logistic regression showed that the odds of having regular menstruation among students with mothers who were educated above the intermediate level is 0.6 times more than those who had mothers with education below the intermediate level. Also the odd of having hypermenorrehoa among married students is 0.15 times more than students who were single. These menstrual dysfunctions could be a symptom of PCOS.

The results of previous studies showed that $50 \%$ of women who had irregular periods had PCOS. In same study it was also showed that having irregular menstruation is associated with increases in the rate of coronary heart disease and diabetes type 2. Also irregular menstruation and Oligomenorrehoa have impact of mental health such as anxiety. ${ }^{[10]}$ Considering the pregnant students and the students who breast feed, less than $10.3 \%$ of the participants had secondary amenorrhea. Finding in Nigeria showed 21\%. ${ }^{[5]}$ This is important indicator to follow for detecting any hormonal disturbance.

In the current study $96.3 \%$ of the participants had dysmenorrhea, these findings supported previous studies that dysmenorrhea was the most prevalent of menstrual problems among students (92\% Saudi, ${ }^{[16]} 76 \%$ Nigeria, ${ }^{[5]} 56.15 \%$ India, ${ }^{[14]}$ $63.1 \%$, Lebanon). ${ }^{[10]}$ In the current study the results showed that among those who had dysmenorrhea, $94.5 \%$ of them, dysmenorrhea reduced their daily activity and $65.7 \%$ of them got absent from their college. These finding are similar to many previous studies. ${ }^{[1,2,14,16]}$ Logistic regression showed that the odds of having dysmenorrhea for single is 0.3 times more than married. Usually menstrual problems have an impact on the life of the women and those who suffer from menorrhagia and dysmenorrhea are more affected. ${ }^{[17]}$

According to the severity of pain and location the finding showed $35.8 \%$ of the participants were suffering from severe dysmenorrhea, $47.5 \%$ moderate and $13.2 \%$ mild. These variances in the pain severity perception among participants could be existed because of the culture diversity and variability in pain edge. ${ }^{[10]}$

Previous study in Nigeria showed that the participants suffered from $36 \%$ low back pain and $76 \%$ abdominal cramp. ${ }^{[5]}$ And in Lebanon $21.4 \%$ abdominal pain, $14.8 \%$ back pain. ${ }^{[10]}$ Whereas in our study $49.6 \%$ of the participants have abdominal pain also $21.5 \%$ back pain and $31.2 \%$ had other pain location.

The results of the current study showed that $8.1 \%$ of students had dysmenorrhea in which the pain location is extended to the anus; this could be a sign of endometriosis. ${ }^{[18]}$ Endometriosis is a problem that should be early detected among women who decided to be pregnant.

Previous studies showed that PMS is one of the most important anxious problems related to menstruation that lead to school absenteeism and one of the common cause of day off work. ${ }^{[18]}$ Another studies revealed serious number of days off in routine work and household activities among women. ${ }^{[19,20]}$

In the current study $95.6 \%$ of the participants had at least 3 symptoms, in which $46.2 \%$ of the participants the symptoms do not disappear by the onset of menstruation and $52.7 \%$ disappear (this percentage is calculated as the one to have PMS) which is relevant to the study in Saudi $(88.5 \%$ had reported PMS). ${ }^{[16]}$

Previous study conducted in India, reported that 56.16\% of the girls participated in the study suffered from PMS. Headache, fatigue, feeling of gaining weight, abdominal bloating, backache, breast heaviness and joint pain were the most common pre-menstrual symptoms experienced by the those girls. Also it has reported that $13.9 \%$ of them were affected on their routine daily life and school attendance. ${ }^{[14]}$

Whereas in our study PMS had more impact, it is usually reduced the productivity among $52.6 \%$ of the participants. Also PMS interfere with hobbies or social activities among $51.2 \%$ of the participants. In addition PMS among $48 \%$ of the participants usually interfere with relationships with others.

Despite menstruation usually is a normal process but sometimes associated with premenstrual and menstrual troubles. These troubles could be very dangerous and lead to loss of work days. ${ }^{[14]}$ In the present study the logistic regression analysis showed that the odds of having PMS among students who were below the 3 rd academic year were 2 times more than those who were above the 3 rd academic year.

The present study has not found significant relations between 
age and any of menstrual problems as other studies showed, maybe because of the small range of age among the students. ${ }^{[10]}$

\section{Impact in nursing}

The study showed that the majority of the undergraduates nursing students had menstrual disorders that associated with their health and had academic effects. There was an increase rate of absenteeism and loss of concentration in academic work which might have impact on school performances as well as the achievement of their life goals.

Nurses play a key role central to public education on health hygiene and personal development, including the maintenance of optimal menstrual hygiene and self-care practices among female adolescents. They always come in contact with this vulnerable group and therefore it is necessary for them to have adequate knowledge as well as becoming role models to this deliquescent group of the society. Thus it becomes as a role to ensure proper education and encouragement of personal hygiene and optimal self-care practices among female adolescents in our society. ${ }^{[16]}$

Therefore there is a need for regular reproductive health programs for female undergraduates including information on menstrual management. ${ }^{[5]}$ Offering that information, treat- ment with good management of the menstrual disorders should be an important element of the programs established for women's health.

\section{Conclusion}

The findings of our current study and other previous studies $^{[2,3,10,16]}$ have reported high prevalence of menstrual problems those problems affect their quality of life and also costly. It is therefore imperative that health care providers most especially nurses increase their anticipatory guidance regarding menstruation and associated disorders. Increasing awareness about menstrual problems directing community especially female and their parents, and including courses on reproductive health in school curriculum may assist in early detection of these disorders.

\section{ACKNOWLEDgements}

The authors show gratitude to all the participants, also appreciate Ms. Iman Adare, from English department of Ibn Sina college for their support and help in reviewing and editing the article.

\section{CONFLicts OF INTEREST Disclosure}

The author declares that there is no conflict of interest.

\section{REFERENCES}

[1] Shiferaw M, Wubshet M, Tegabu D. Menstrual problems and associated factors among students of Bahir Dar University, Amhara National Regional State, Ethiopia: A cross-sectional survey. Pan African Medical Journal. 2014; 17: 246. PMid:25309646 http: //dx.doi.org/10.11604/pamj.2014.17.246.2230

[2] Esimai OA, Omoniyi Esan GO. Awareness of Menstrual Abnormality Amongst College Students in Urban Area of Ile-Ife, Osun State, Nigeria, Indian J Community Med. 2010 Jan; 35(1): 63-66. PMid:20606922 http://dx.doi.org/10.4103/0970-0218.62 559

[3] Rigon F, et al. Menstrual pattern and menstrual disorders among adolescents: an update of the Italian data. Italian Journal of Pediatrics. 2012; 38: 38. http://www.ijponline.net/content/38/1/3 8 PMid:22892329 http: //dx.doi.org/10.1186/1824-7288-3 8-38

[4] Bata SM. Age at menarche, menstrual patterns, and menstrual characteristics in Jordanian adolescent girls. International Journal of Gynecology and Obstetrics. 2012; 119: 281-283. PMid:22981340 http://dx.doi.org/10.1016/j.ijgo.2012.07.009

[5] Olowokere EA, et al. Menstrual disorders: The implications on health and academic activities of female undergraduates in a federal university in Nigeria. Journal of Nursing Education and Practice. 2014; 4(5). http://dx.doi.org/10.5430/jnep.v4n5p126

[6] Popat VB, et al. The menstrual cycle: a biological marker of general health in adolescents. Ann N Y Acad Sci. 2008; 1135: 43-
51. PMid:18574207 http://dx.doi.org/10.1196/annals.14 29.040

[7] Symphorosa SC, et al. Menstrual problems and health-seeking behavior in Hong Kong Chinese girls, Hong Kong Med J. 2009; 15 : 18-23.

[8] Kumar D. Menstrual Pattern among Unmarried Women from Northern India. J Clin Diagn Res. 2013 Sep; 7(9): 1926-1929. PMid:24179899

[9] Omidvar SH, Begum KH. Menstrual pattern among unmarried women from south India. J Nat Sci Biol Med. 2011 Jul-Dec; 2(2): 174-179. PMid:22346231 http://dx.doi.org/10.4103/0 976-9668. 92329

[10] Karout N, et al. Prevalence and pattern of menstrual disorders among Lebanese nursing students. EMHJ. 2012; 18(4).

[11] Palep-Singh M, Prentice A. Epidemiology of abnormal uterine bleeding. Best Practice \& Research. Clinical Obstetrics \& Gynecology. 2007; 21: 887-890. PMid:17936074 http://dx.doi.org/10.10 $16 /$ j.bpobgyn. 2007.03 .012

[12] Walraven G, et al. Menstrual disorders in rural Gambia. Studies in Family Planning. 2002; 33: 261-268. http://dx.doi.org/10.11 $11 / j .1728-4465.2002 .00261 . x$

[13] Harlow SD, Campbell OMR. Menstrual dysfunction: a missed opportunity for improving reproductive health in developing countries. Reproductive Health Matters. 2000; 8: 142-147. http://dx.doi.o $\mathrm{rg} / 10.1016 / \mathrm{S} 0968-8080$ (00) 90016-8 
[14] Dambhare GD, et al. Age at Menarche and Menstrual Cycle Pattern among School Adolescent Girls in Central India. Global Journal of Health Science. 2012; 4(1).

[15] Dhingra R, Anil Kumar. Knowledge and Practices Related to Menstruation among Tribal (Gujjar) Adolescent Girls. Ethno-med. 2009; 3(1): 43-48.

[16] Hasanein N, Mohamed Diab S. Menstrual Disorders and Hygienic Self Care Practices among Adolescent Girls in Preparatory year at A1-Jouf University. IOSR Journal of Nursing and Health Science. 2015; 4(3).

[17] Cakir M, Okten A. Menstrual pattern and common menstrual disorders among university students in Turkey. Pediatrics International.
2007; 49: 938-942. PMid:18045301

[18] Drife JO, Magowan BA. Normal Menstrual Cycle. Clinical Obstetrics and Gynecology. Saunders publication. 2004; 121.

[19] Dean BB, Borenstein JE. A prospective assessment investigating the relationship between work productivity and impairment with premenstrual syndrome. J Occup Environ Med. 2004; 46: 649656. PMid:15247803 http://dx.doi.org/10.1097/01.jom.00 00131796.62115 .84

[20] Robinson RL, Swindle RW. Premenstrual symptom severity: impact on social functioning and treatment seeking behavior. J Womens Health Gend Based Med. 2000; 9: 757-768. PMid:11025868 http://dx.doi.org/10.1089/15246090050147736 